\title{
Commentary: What was then is not now
}

\author{
Dawn S. Hui, MD, ${ }^{a}$ and Richard Lee, MD, MBA ${ }^{\mathrm{b}}$
}

In cardiac surgery, outcomes reporting for atrial fibrillation (AF) is challenging. For other cardiac operations, failure is defined by discrete, easily measurable criteria: graft patency for coronary artery bypass graft, recurrent regurgitation for valvular repair, and bioprosthetic degeneration for valve replacement. Repeat intervention also serves as a proxy for failure, although it may be subject to selection bias. For surgical ablation, however, detection of failure is more difficult by several magnitudes. Unless a patient has a permanent pacemaker (itself an undesirable outcome of $\mathrm{AF}$ ablation), rhythm monitoring is limited, and true $\mathrm{AF}$ burden cannot be captured. Definitions of failure have changed over time with technology, and what constitutes a clinically significant failure remains debatable.

In this edition of the Journal, Khiabani and colleagues $^{1}$ publish on their 15 -year institutional experience with the Cox-maze IV (CM-IV). The impact of this paper on our collective knowledge of surgical ablation is substantial. It is one of the largest single-institution studies, with late follow-up from a center with experience and expertise. The findings confirm those of many smaller studies, namely that the CM-IV is highly effective in the short- and mid-term and that left atrial size and nonparoxysmal AF are risk factors for recurrence, among others. That more than $80 \%$ of the operations were done by a single surgeon with a consistent lesion set is a strength of the paper, as

\footnotetext{
From the a Department of Cardiothoracic Surgery, University of Texas Health Science Center at San Antonio, San Antonio, Tex; and ${ }^{\mathrm{b}}$ Division of Cardiothoracic Surgery, Department of Surgery, Medical College of Georgia, Augusta University, Augusta, Ga. Disclosures: The authors reported no conflicts of interest.

The Journal policy requires editors and reviewers to disclose conflicts of interest and to decline handling or reviewing manuscripts for which they may have a conflict of interest. The editors and reviewers of this article have no conflicts of interest.

Received for publication April 22, 2020; accepted for publication April 23, 2020; available ahead of print May 4, 2020.

Address for reprints: Richard Lee, MD, MBA, Department of Surgery, Medical College of Georgia, 1120 15th St, BA-4300, Augusta, GA 30912 (E-mail: RICKLEE@ augusta.edu).

J Thorac Cardiovasc Surg 2022;163:642-3

$0022-5223 / \$ 36.00$

Copyright (c) 2020 by The American Association for Thoracic Surgery

https://doi.org/10.1016/j.jtcvs.2020.04.094
}

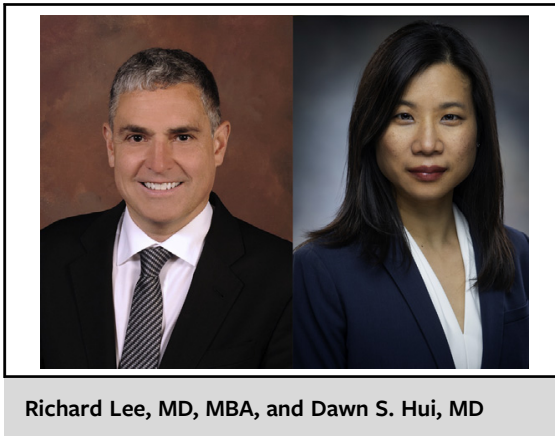

CENTRAL MESSAGE

A large study from a center of

expertise and experience con-

tributes to our understanding of

AF ablation, but discordance with

previous findings raises ques-

tions about the choice of

nonstandard end points.

it removes operator confounding. Interestingly, the findings of this paper differ somewhat from their 2015 study. ${ }^{2}$ In the previous series, preoperative $\mathrm{AF}$ type did not predict late failure, whereas the current series shows nonparoxysmal $\mathrm{AF}$ to be a predictor of late recurrence. Further, the previous study also found duration of preoperative AF a significant predictor, with failure probability increasing as AF duration increased. In the current paper, AF duration was not a significant predictor.

These discordant findings were despite similar demographics, surgical techniques, selection criteria, and statistical analytic methods in the 2 papers (as would be expected for same-institution studies). Thus, we would be interested to hear the authors' statements on why these 2 excellent studies differed on these points. Possibly more problematic is the new end point that they propose. Freedom from atrial tachyarrhythmia recurrence was analyzed in 2 waysfreedom from recurrence at each time point, and freedom from recurrence over the entire study period. Although the former may be more clinically valid as the authors opine, it does not fit in the harmonized outcome measures schema endorsed by the Heart Rhythm Society. ${ }^{3}$ This creates a dilemma in comparing this study with other ablation and surgical literature.

There are a few other notable aspects. First, the strict definition of CM-IV was not applied to the entire cohort, with 
about $10 \%$ of patients having only left-sided lesions (an increase in proportion compared with their 2015 paper). However, this did allow study of the impact on permanent pacemaker needs, with biatrial lesions having a 3.61 odds ratio of pacemaker placement. Also of note is the $38 \%$ loss to follow-up at 10 years. Only 42 patients had complete follow-up in years $1-10$, and only $31 \%$ to $39 \%$ had prolonged monitoring in post-ablation years 8-10. Thus, long-term data remain limited. Third, reintervention is often considered a factor in defining procedural failure. Unlike aortic or valve surgery, patients who undergo surgical ablation are rarely treated with repeat surgery for $\mathrm{AF}$ recurrence. In the current study, data on postsurgical catheter-based therapies for recurrence were not collected. Thus, to attribute ablation success solely to the surgical CM-IV may be an overreach. This would be especially important in counseling patients on the efficacy of the procedure.
Finally, whether this study will impact the nonsurgical world is in question, despite the excellent results. Head-to-head comparisons with catheter ablation remain scant, and comparisons across studies are methodologically unsound. Nevertheless, the authors are to be congratulated on their foresight and ongoing commitment to refining not only the surgical technique of the Cox-maze procedure but in refining their outcomes reporting and our understanding of surgical ablation for AF.

\section{References}

1. Khiabani AJ, MacGregor RM, Bakir NH, Manghelli JL, Sinn LA, Maniar HS et al. The long-term outcomes and durability of the Cox-maze IV procedure for atrial fibrillation. J Thorac Cardiovasc Surg. 2022;163:629-41.e7.

2. Henn MC, Lancaster TS, Miller JR, Sinn LA, Schuesller RB, Moon MR, et al. Late outcomes after the Cox maze IV procedure for atrial fibrillation. J Thorac Cardiovasc Surg. 2015;150:1168-78.

3. Calkins H, Gliklich RE, Leavy MB, Piccini JP, Hsu JC, Mohanty S, et al. Harmonized outcome measures for use in atrial fibrillation patient registries and clinical practice. Heart Rhythm. 2019;16:e3-16.
See Article page 629.

\section{Commentary: Do teach old dogs new tricks}

\author{
Leonid Sternik, MD
}

First of all, I wish to thank Khiabani and colleagues ${ }^{1}$ for their great efforts in the field of surgical treatment of atrial fibrillation (AF). This retrospective study is a kind of summary of their work. The authors describe 853 patients who underwent surgical treatment of $\mathrm{AF}$ at the same institution between 2003 and 2018. Interestingly, the classic technique of surgical AF ablation, the cut-and-sew maze (Cox-maze III), was developed by Cox and his colleagues more than 30 years at the same institution. ${ }^{2}$ Cox-maze III was a very

\footnotetext{
From the Department of Cardiac Surgery, Sheba Medical Center, Affiliated to TelAviv University, Tel-Hashomer, Israel.

Disclosures: The author reported no conflicts of interest.

The Journal policy requires editors and reviewers to disclose conflicts of interest and to decline handling or reviewing manuscripts for which they may have a conflict of interest. The editors and reviewers of this article have no conflicts of interest.

Received for publication April 17, 2020; accepted for publication April 17, 2020; available ahead of print May 4, 2020.

Address for reprints: Leonid Sternik, MD, Department of Cardiac Surgery, Sheba

Medical Center, Ramat Gan, Israel (E-mail: leosternik@hotmail.com).

J Thorac Cardiovasc Surg 2022;163:643-4

$0022-5223 / \$ 36.00$

Copyright (c) 2020 by The American Association for Thoracic Surgery

https://doi.org/10.1016/j.jtcvs.2020.04.093
}

\section{Check for updates}

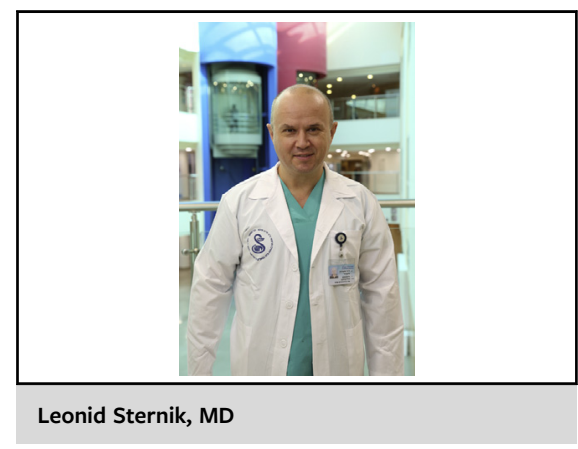

CENTRAL MESSAGE

Cox-maze IV is an example of a new technology, based on old Cox-maze III and makes it easier to employ. Experienced "old" surgeons have to learn these new "tricks" and educate their young colleagues.

efficient procedure but not easy to perform and hasn't spread worldwide. ${ }^{1}$ The Cox-maze IV, developed by Damiano and his team, is based on the lesion set of Cox-maze III, but many lesion lines are performed by radiofrequency and 